\title{
Asymptotic Dichotomy in a Class of Odd-Order Nonlinear Differential Equations with Impulses
}

\author{
Kunwen Wen and Lijun Pan \\ Department of Mathematics, Jiaying University, Meizhou, Guangdong 514015, China \\ Correspondence should be addressed to Kunwen Wen; wenkunwen@126.com
}

Received 26 September 2013; Accepted 2 December 2013

Academic Editor: Ting Chen

Copyright (c) 2013 K. Wen and L. Pan. This is an open access article distributed under the Creative Commons Attribution License, which permits unrestricted use, distribution, and reproduction in any medium, provided the original work is properly cited.

\begin{abstract}
We investigate the oscillatory and asymptotic behavior of a class of odd-order nonlinear differential equations with impulses. We obtain criteria that ensure every solution is either oscillatory or (nonoscillatory and) zero convergent. We provide several examples to show that impulses play an important role in the asymptotic behaviors of these equations.
\end{abstract}

\section{Introduction}

Impulsive effect, likewise, exists in a wide variety of evolutionary processes in which states are changed abruptly at certain moments in time, involving such fields as medicine and biology, economics, mechanics, electronics, telecommunications, and so forth. It has been observed that the solutions of quite a few first-or second-order impulsive differential equations are either oscillatory or (nonoscillatory and) zero convergent (see, e.g., [1-10]). For example, Bainov et al. studied the oscillation properties of first-order impulsive differential equations with deviating arguments [3]. Especially in [4], Chen investigated oscillations of second-order nonlinear differential with impulses, and he promposed that the impulses may change the oscillatory behavior of an equation. Based on [4], the authors were devoted to oscillations of impulsive differential equations (see, e.g., [510]). Such a dichotomy may yield useful information in real problems. The implications of this dichotomy are applied to the deflection of an elastic beam [11]. Thus, it is of interest to see whether similar dichotomies occur in different types of impulsive differential equations.

One such type consists of impulsive differential equations which are important in the simulation of processes with jump conditions. But papers devoted to the study of asymptotic behaviors of higher order equations with impulses are quite rare. For this reason, Wen et al. studied in [12] the dichotomous properties of the following third-order nonlinear differential equation with impulses:

$$
\begin{gathered}
\left(r(t) x^{\prime \prime}(t)\right)^{\prime}+f(t, x)=0, \quad t \geq t_{0}, \quad t \neq t_{k}, \\
x^{(i)}\left(t_{k}^{+}\right)=g_{k}^{[i]}\left(x^{(i)}\left(t_{k}\right)\right), \quad i=0,1,2 ; k=1,2, \ldots, \\
x^{(i)}\left(t_{0}^{+}\right)=x_{0}^{(i)}, \quad i=0,1,2,
\end{gathered}
$$

where $x^{(0)}(t)=x(t), 0 \leq t_{0}<t_{1}<\cdots<t_{k}<\cdots$ such that $\lim _{k \rightarrow \infty} t_{k}=\infty$. On the other hand, in [13], Chen and Wen investigated the oscillatory and asymptotic behaviors for odd-order nonlinear differential equations with impulses of the form

$$
\begin{gathered}
x^{(2 n+1)}(t)+p(t) x(t)=0, \quad t \geq t_{0}, \quad t \neq t_{k}, \\
x^{(i)}\left(t_{k}^{+}\right)=a_{k}^{[i]} x^{(i)}\left(t_{k}\right), \quad i=0,1, \ldots, 2 n ; k=1,2, \ldots, \\
x^{(i)}\left(t_{0}^{+}\right)=x_{0}^{(i)}, \quad i=0,1, \ldots, 2 n,
\end{gathered}
$$

where $n$ is a positive integer and $0 \leq t_{0}<t_{1}<\cdots<t_{k}<\cdots$ such that $\lim _{k \rightarrow+\infty} t_{k}=+\infty$. They obtained some interesting results for assuring that every bounded solution of (2) is either oscillatory or nonoscillatory and zero convergent. 
In this paper, we will study a class of odd-order nonlinear differential equations with impulses of the form

$$
\begin{gathered}
\left(r(t) x^{(2 n)}(t)\right)^{\prime}+f(t, x)=0, \quad t \geq t_{0}, \quad t \neq t_{k}, \\
x^{(i)}\left(t_{k}^{+}\right)=g_{k}^{[i]}\left(x^{(i)}\left(t_{k}\right)\right), \quad i=0,1, \ldots, 2 n ; k=1,2, \ldots, \\
x^{(i)}\left(t_{0}^{+}\right)=x_{0}^{[i]}, \quad i=0,1, \ldots, 2 n,
\end{gathered}
$$

where $x^{(0)}(t)=x(t), n$ is a positive integer, and $0 \leq t_{0}<t_{1}<$ $\cdots<t_{k}<\cdots$ such that $\lim _{k \rightarrow+\infty} t_{k}=+\infty$,

$$
\begin{aligned}
& x^{(i)}\left(t_{k}\right)=\lim _{h \rightarrow 0^{-}} \frac{x^{(i-1)}\left(t_{k}+h\right)-x^{(i-1)}\left(t_{k}\right)}{h}, \\
& x^{(i)}\left(t_{k}^{+}\right)=\lim _{h \rightarrow 0^{+}} \frac{x^{(i-1)}\left(t_{k}+h\right)-x^{(i-1)}\left(t_{k}^{+}\right)}{h} .
\end{aligned}
$$

By a solution of (3), we mean a real function $x=x(t)$ defined on $\left[t_{0},+\infty\right)$ such that

(I) $x^{(i)}\left(t_{0}^{+}\right)=x_{0}^{[i]}$ for $i=0,1, \ldots, 2 n$;

(II) $x^{(i)}(t), i=0,1, \ldots, 2 n$, and $\left(r(t) x^{(2 n)}(t)\right)^{\prime}$ are continuous on $\left[t_{0},+\infty\right) \backslash\left\{t_{k}\right\}$; for $i=0,1, \ldots, 2 n, x^{(i)}\left(t_{k}^{+}\right)$ and $x^{(i)}\left(t_{k}^{-}\right)$exist, $x^{(i)}\left(t_{k}^{-}\right)=x^{(i)}\left(t_{k}\right)$ and $x^{(i)}\left(t_{k}^{+}\right)=$ $g_{k}^{[i]}\left(x^{(i)}\left(t_{k}\right)\right)$ for any $t_{k}$;

(III) $x(t)$ satisfies $\left(r(t) x^{(2 n)}(t)\right)^{\prime}+f(t, x(t))=0$ at each point $t \in\left[t_{0},+\infty\right) \backslash\left\{t_{k}\right\}$.

A solution of (3) is said to be nonoscillatory if it is eventually positive or eventually negative. Otherwise, it is said to be oscillatory.

We will establish oscillatory and asymptotic results of (3) based on combinations of the following conditions.

(i) $r(t)>0$ and $r(t)$ is continuous on $\left[t_{0},+\infty\right) ; f(t, x)$ is continuous on $\left[t_{0},+\infty\right) \times(-\infty,+\infty), x f(t, x)>0$ for $x \neq 0$, and $f(t, x) / \varphi(x) \geqslant p(t)$, where $p(t)$ is positive and continuous on $\left[t_{0},+\infty\right)$ and $\varphi$ is differentiable in $(-\infty,+\infty)$ such that $\varphi^{\prime}(x) \geq 0$ for $x \in(-\infty,+\infty)$.

(ii) For $k=1,2, \ldots, g_{k}^{[i]}(x)$ are continuous in $(-\infty,+\infty)$ and there exist positive numbers $a_{k}^{[i]}, b_{k}^{[i]}$ such that

$$
a_{k}^{[i]} \leq g_{k}^{[i]}(x) / x \leq b_{k}^{[i]}, \quad i=0,1,2, \ldots, 2 n .
$$

(iii)

$$
\begin{gathered}
\int_{t_{0}}^{+\infty} \prod_{t_{0}<t_{k}<s} \frac{a_{k}^{[i]}}{b_{k}^{[i-1]}} d s=+\infty ; \quad i=1,2, \ldots, 2 n-1, \\
\int_{t_{0}}^{+\infty} \frac{1}{r(s)} \prod_{t_{0}<t_{k}<s} \frac{a_{k}^{[2 n]}}{b_{k}^{[2 n-1]}} d s=+\infty .
\end{gathered}
$$

Our plan is the following. We first obtain three theorems (Theorems 1-3) to ensure every solution of (3) is either oscillatory or (nonoscillatory and) zero convergent. We will also illustrate our results with several examples. As applications of our results, we state three corollaries (Corollaries 5-7). These corollaries are new even for the special case (2).

\section{Main Results}

The main results of the paper are as follows.

Theorem 1. Assume that the conditions (i)-(iii) hold. Suppose further that there exists a positive integer $k_{0}$ such that for $k \geq$ $k_{0}, a_{k}^{[0]} \geq 1$,

$$
\begin{gathered}
\sum_{k=1}^{+\infty}\left(b_{k}^{[0]}-1\right)<+\infty, \\
\int_{t_{0}}^{+\infty} \prod_{t_{0}<t_{k}<s} \frac{1}{b_{k}^{[2 n]}} p(s) d s=+\infty .
\end{gathered}
$$

Then every solution of (3) is either oscillatory or (nonoscillatory and) zero convergent.

Theorem 2. Assume that the conditions (i)-(iii) hold and that $\varphi(a b) \geq \varphi(a) \varphi(b)$ for any $a b>0$. Suppose further that there exists a positive integer $k_{0}$ such that for $k \geq k_{0}$,

$$
\begin{gathered}
b_{k}^{[0]} \leq 1, \quad b_{k}^{[2 n]} \leq 1, \quad b_{k}^{[2 n]} \leq \varphi\left(a_{k}^{[0]}\right), \\
\int_{t_{0}}^{+\infty} p(s) d s=+\infty .
\end{gathered}
$$

Then every solution of (3) is either oscillatory or (nonoscillatory and) zero convergent.

Theorem 3. Assume that the conditions (i)-(iii) hold and that $\varphi(a b) \geq \varphi(a) \varphi(b)$ for any $a b>0$. Suppose further that $b_{k}^{[2 n]} \leq$ $a_{k}^{[0]},\left\{\prod_{k=1}^{n} b_{k}^{[0]}\right\}$ is bounded,

$$
\begin{aligned}
\sum_{k=1}^{+\infty} \max & \left\{\left|a_{k}^{[0]}-1\right|,\left|b_{k}^{[0]}-1\right|\right\}<+\infty, \\
& \sum_{k=1}^{+\infty}\left|b_{k}^{[2 n]}-1\right|<+\infty, \\
& \int_{t_{0}}^{+\infty} p(s) d s=+\infty .
\end{aligned}
$$

Then every solution of (3) is either oscillatory or (nonoscillatory and) zero convergent.

Remark 4. When $n=1$, (3) reduces to (1). Our Theorems 1-3 are Theorem 2.1, Theorem 2.3, Theorem 2.4 in [12], respectively. So our results generalize and contain results in [12].

Next, for (2), we will also be able to obtain some new results. It is easy to see that (2) has the form of (3) by setting $r(t)=1, f(t, x(t))=p(t) x(t)$ and $g_{k}^{[i]}\left(x^{(i)}\left(t_{k}\right)\right)=a_{k}^{[i]} x^{(i)}\left(t_{k}\right)$ for $i=0,1, \ldots, 2 n$ and $k=1,2, \ldots$ Let

$$
\begin{aligned}
a_{k}^{[i]} & =b_{k}^{[i]}, \quad i=0,1, \ldots, 2 n ; k=1,2, \ldots, \varphi(x) \\
& =x .
\end{aligned}
$$

Our Theorems 1-3 can directly lead us to the following corollaries for (2). 
Corollary 5. Assume that the conditions (i)-(iii) hold. Suppose further that there exists a positive integer $k_{0}$ such that for $k \geq k_{0}, a_{k}^{[0]} \geq 1$,

$$
\begin{gathered}
\sum_{k=1}^{+\infty}\left(a_{k}^{[0]}-1\right)<+\infty, \\
\int_{t_{0}}^{+\infty} \prod_{t_{0}<t_{k}<s} \frac{1}{a_{k}^{[2 n]}} p(s) d s=+\infty .
\end{gathered}
$$

Then every solution of (2) is either oscillatory or (nonoscillatory and) zero convergent.

Corollary 6. Assume that the conditions (i)-(iii) hold. Suppose further that there exists a positive integer $k_{0}$ such that for $k \geq k_{0}$,

$$
\begin{gathered}
a_{k}^{[0]} \leq 1, \quad a_{k}^{[2 n]} \leq 1, \quad a_{k}^{[2 n]} \leq a_{k}^{[0]} \\
\int_{t_{0}}^{+\infty} p(s) d s=+\infty .
\end{gathered}
$$

Then every solution of (2) is either oscillatory or (nonoscillatory and) zero convergent.

Corollary 7. Assume that the conditions (i)-(iii) hold. Suppose further that $a_{k}^{[2 n]} \leq a_{k}^{[0]},\left\{\prod_{k=1}^{n} a_{k}^{[0]}\right\}$ is bounded,

$$
\begin{aligned}
& \sum_{k=1}^{+\infty}\left|a_{k}^{[0]}-1\right|<+\infty, \\
& \sum_{k=1}^{+\infty}\left|a_{k}^{[2 n]}-1\right|<+\infty \\
& \int_{t_{0}}^{+\infty} p(s) d s=+\infty .
\end{aligned}
$$

Then every solution of (2) is either oscillatory or (nonoscillatory and) zero convergent.

Remark 8. We note that the above corollaries for ensuring every solution of (2) to be either oscillatory or tend to zero with fixed sign eventually is also new for (2).

Example 9. Consider the equation

$$
\begin{gathered}
x^{\prime \prime \prime}(t)+\frac{3}{8} t x^{3}(t)=0, \quad t \geq \frac{1}{2}, \quad t \neq k, \\
x^{(i)}\left(k^{+}\right)=\left(1+\frac{1}{k^{2}}\right) x^{(i)}(k), \quad i=0,1,2 ; k=1,2, \ldots, \\
x\left(\frac{1}{2}\right)=x_{0}, \quad x^{\prime}\left(\frac{1}{2}\right)=x_{0}^{[1]}, \quad x^{\prime \prime}\left(\frac{1}{2}\right)=x_{0}^{[2]},
\end{gathered}
$$

where $a_{k}^{[i]}=b_{k}^{[i]}=\left(1+\left(1 / k^{2}\right)\right) \geq 1$ for $i=0,1,2 ; r(t)=$ $1, p(t)=(3 / 8) t, t_{k}=k$, and $\varphi(x)=x^{3}$. It is not difficult to see that conditions (i)-(iii) are satisfied. Furthermore,

$$
\begin{gathered}
\sum_{k=1}^{+\infty} \max \left\{\left|a_{k}^{[0]}-1\right|,\left|b_{k}^{[0]}-1\right|\right\}=\sum_{k=1}^{+\infty} \frac{1}{k^{2}}<+\infty \\
\int_{t_{0}}^{+\infty} \prod_{t_{0}<t_{k}<s} \frac{1}{b_{k}^{[2]}} p(s) d s=\int_{1 / 2}^{+\infty} \frac{3}{8} \prod_{1 / 2<t_{k}<s} \frac{k^{2}}{k^{2}+1} s d s=+\infty .
\end{gathered}
$$

Thus by Theorem 1, every solution of (14) is either oscillatory or (nonoscillatory and) zero convergent.

Example 10. Consider the equation

$$
\begin{gathered}
\left((2-\sin t) g(t) x^{(4)}(t)\right)^{\prime}+t x^{3}(t)=0, \quad t \geq \frac{1}{2}, t \neq k, \\
x^{(i)}\left(k^{+}\right)=\left(1+\frac{1}{k^{2}}\right) x^{(i)}(k), \\
x^{(4)}\left(k^{+}\right)=\left(1-\frac{1}{k^{2}}\right) x^{(4)}(k), \quad i=0,1,2,3 ; k=1,2, \ldots, \\
x^{(j)}\left(\frac{1}{2}\right)=x_{0}^{[j]}, \quad j=0,1,2,3,4,
\end{gathered}
$$

where $a_{k}^{[i]}=b_{k}^{[i]}=\left(1+\left(1 / k^{2}\right)\right)$ for $i=0,1,2,3, a_{k}^{[4]}=b_{k}^{[4]}=$ $\left(1-\left(1 / k^{2}\right)\right) ; p(t)=t, t_{k}=k, \varphi(x)=x^{3}$, and

$$
r(t)=(2-\sin t) g(t)
$$

where

$$
g(t)=\left|t-k-\frac{1}{2}\right|+1, \quad t \in[k, k+1), k=1,2, \ldots
$$

Here, we do not assume that $r(t)$ is bounded, monotonic, or differentiable. It is not difficult to see that conditions (i)-(iii) are satisfied. Furthermore,

$$
\begin{gathered}
b_{k}^{[4]}=\left(1-\frac{1}{k^{2}}\right) \leq\left(1+\frac{1}{k^{2}}\right)=a_{k}^{[0]}, \\
\sum_{k=1}^{+\infty} \max \left\{\left|a_{k}^{[0]}-1\right|,\left|b_{k}^{[0]}-1\right|\right\} \\
=\sum_{k=1}^{+\infty} \frac{1}{k^{2}}<+\infty, \\
\sum_{k=1}^{+\infty}\left|b_{k}^{[4]}-1\right|=\sum_{k=1}^{+\infty} \frac{1}{k^{2}}<+\infty \\
\int_{t_{0}}^{+\infty} p(s) d s=\int_{1 / 2}^{+\infty} \frac{1}{s} d s=+\infty .
\end{gathered}
$$

Thus by Theorem 3, every solution of (16) is either oscillatory or (nonoscillatory and) zero convergent. 
Example 11. Consider the equation

$$
\begin{gathered}
\left(t^{-1} x^{(4)}(t)\right)^{\prime}+\left(t^{-1}-t^{-2}\right) x(t)=0, \quad t \geq \frac{1}{2}, t \neq k, \\
x\left(k^{+}\right)=x(k), \quad x^{\prime}\left(k^{+}\right)=x^{\prime}(k), \\
x^{(i)}\left(k^{+}\right)=\frac{k}{k+1} x^{(i)}(k), \quad i=2,3,4 ; k=1,2, \ldots, \\
x^{(j)}\left(\frac{1}{2}\right)=x_{0}^{[j]}, \quad j=0,1,2,3,4,
\end{gathered}
$$

where $a_{k}^{[0]}=b_{k}^{[0]}=a_{k}^{[1]}=b_{k}^{[1]}=1, a_{k}^{[i]}=b_{k}^{[i]}=k /(k+1)$ for $i=2,3,4 ; p(t)=t^{-1}-t^{-2}, r(t)=t^{-1}, t_{k}=k ; \varphi(x)=x$. It is not difficult to see that conditions (i)-(iii) are satisfied. Furthermore,

$$
\begin{gathered}
b_{k}^{[2 n]}=\frac{k}{k+1} \leq 1=\varphi\left(a_{k}^{[0]}\right), \\
\int_{t_{0}}^{+\infty} p(s) d s=\int_{1 / 2}^{+\infty}\left(\frac{1}{s}-\frac{1}{s^{2}}\right) d s=+\infty .
\end{gathered}
$$

Thus, by Theorem 2, every solution of (20) is either oscillatory or (nonoscillatory and) zero convergent. But the ordinary differential equation

$$
\left(t^{-1} x^{(4)}(t)\right)^{\prime}+\left(t^{-1}-t^{-2}\right) x(t)=0,
$$

has a solution $x(t)=-e^{t}$ which tends to $-\infty$ as $t \rightarrow+\infty$. This example shows that impulses play an important role in oscillatory and asymptotic behaviors of equations.

\section{Proofs}

To prove our Theorems, we need the following Lemmas.

Lemma 12 (Lakshmikantham et al. [1]). Assume that

$\left(\mathrm{H}_{0}\right) m \in P C^{\prime}\left(R^{+}, R\right)$ and $m(t)$ is left-continuous at $t_{k}$ for $k=1,2, \ldots$

$$
\left(\mathrm{H}_{1}\right) \text { for } t_{k}, k=1,2, \ldots \text { and } t \geq t_{0} \text {, }
$$

$$
\begin{aligned}
& m^{\prime}(t) \leq p(t) m(t)+q(t), \quad t \neq t_{k} \\
& m\left(t_{k}^{+}\right) \leq d_{k} m\left(t_{k}\right)+b_{k}
\end{aligned}
$$

where $p, q \in P C\left(R^{+}, R\right), d_{k} \geq 0$, and $b_{k}$ are real constants. Then for $t \geq t_{0}$,

$$
\begin{aligned}
m(t) \leq & m\left(t_{0}\right) \prod_{t_{0}<t_{k}<t} d_{k} \exp \left(\int_{t_{0}}^{t} p(s) d s\right) \\
& +\sum_{t_{0}<t_{k}<t}\left(\prod_{t_{k}<t_{j}<t} d_{j} \exp \left(\int_{t_{k}}^{t} p(s) d s\right)\right) b_{k} \\
& +\int_{t_{0}}^{t}\left(\prod_{s<t_{k}<t} d_{k}\right) \exp \left(\int_{s}^{t} p(\sigma) d \sigma\right) q(s) d s .
\end{aligned}
$$

Remark 13. If the inequalities in (23) are reversed, then the inequality in (24) should be reversed as well.

Lemma 14. Suppose that conditions (i)-(iii) hold and $x(t)$ is a solution of (3). One has the following statements:

(a) if there exists some $T \geq t_{0}$ such that $x^{(2 n)}(t)>0$ and $\left(r(t) x^{(2 n)}(t)\right)^{\prime} \geq 0$ for $t \geq T$, then there exists some $T_{1} \geq T$ such that $x^{(2 n-1)}(t)>0$ for $t \geq T_{1}$;

(b) if there exists $i \in\{1,2, \ldots, 2 n-1\}$ and some $T \geq t_{0}$ such that $x^{(i)}(t)>0$ and $x^{(i+1)}(t) \geq 0$ for $t \geq T$, then there exists some $T_{1} \geq T$ such that $x^{(i-1)}(t)>0$ for $t \geq T_{1}$.

Proof. First of all, we will prove the result of (a) to be true. Without loss of generality, we may assume that $x^{(2 n)}(t)>0$ and $\left(r(t) x^{(2 n)}(t)\right)^{\prime} \geq 0$ for $t \geq t_{0}$. We assert that there exists some $j$ such that $x^{(2 n-1)}\left(t_{j}\right)>0$ for $t_{j} \geq t_{0}$. If this is not true, then for any $t_{k}>t_{0}$, we have $x^{(2 n-1)}\left(t_{k}\right) \leq 0$. Since $x^{(2 n-1)}(t)$ is increasing on intervals of the form $\left(t_{k}, t_{k+1}\right]$, we see that $x^{(2 n-1)}(t) \leq 0$ for $t \geq t_{0}$. Since $r(t) x^{(2 n)}(t)$ is increasing on intervals of the form $\left(t_{k}, t_{k+1}\right]$, we see that for $t \in\left(t_{1}, t_{2}\right]$,

$$
r(t) x^{(2 n)}(t) \geq r\left(t_{1}\right) x^{(2 n)}\left(t_{1}^{+}\right)
$$

that is,

$$
x^{(2 n)}(t) \geq \frac{r\left(t_{1}\right)}{r(t)} x^{(2 n)}\left(t_{1}^{+}\right) .
$$

In particular,

$$
x^{(2 n)}\left(t_{2}\right) \geq \frac{r\left(t_{1}\right)}{r\left(t_{2}\right)} x^{(2 n)}\left(t_{1}^{+}\right)
$$

Similarly, for $t \in\left(t_{2}, t_{3}\right]$, we have

$$
\begin{aligned}
x^{(2 n)}(t) & \geq \frac{r\left(t_{2}\right)}{r(t)} x^{(2 n)}\left(t_{2}^{+}\right) \\
& \geq \frac{r\left(t_{2}\right)}{r(t)} a_{2}^{(2 n)} x^{(2 n)}\left(t_{2}\right) \\
& \geq \frac{r\left(t_{1}\right)}{r(t)} a_{2}^{(2 n)} x^{(2 n)}\left(t_{1}^{+}\right) .
\end{aligned}
$$

By induction, we know that

$$
x^{(2 n)}(t) \geq \frac{r\left(t_{1}\right)}{r(t)} \prod_{t_{1}<t_{k}<t} a_{k}^{(2 n)} x^{(2 n)}\left(t_{1}^{+}\right), \quad t \neq t_{k} .
$$

From condition (ii), we have

$$
x^{(2 n-1)}\left(t_{k}^{+}\right) \geq b_{k}^{[2 n-1]} x^{(2 n-1)}\left(t_{k}\right), \quad t>t_{1}, \quad k=2,3, \ldots
$$


It follows from (29), (30), and Lemma 12, that for $t \geq t_{1}$,

$$
\begin{array}{r}
x^{(2 n-1)}(t) \geq \prod_{t_{1}<t_{k}<t} b_{k}^{[2 n-1]}\left\{x^{(2 n-1)}\left(t_{1}^{+}\right)+x^{(2 n)}\left(t_{1}^{+}\right) r\left(t_{1}\right)\right. \\
\left.\quad \times \int_{t_{1}}^{t} \frac{1}{r(s)} \prod_{t_{1}<t_{k}<s} \frac{a_{k}^{[2 n]}}{b_{k}^{[2 n-1]}} d s\right\} .
\end{array}
$$

Note that $a_{k}^{[i]}>0, b_{k}^{[i]}>0$, and the second equality of condition (iii) hold. Thus, we get $x^{(2 n-1)}(t)>0$ for all sufficiently large $t$, which is contrary to $x^{(2 n-1)}(t) \leq 0$ for $t \geq t_{0}$. So there exists some $j$ such that $t_{j} \geq t_{0}$ and $x^{(2 n-1)}\left(t_{j}\right)>0$. Since $x^{(2 n-1)}(t)$ is increasing on intervals of the form $\left(t_{j+\lambda}, t_{j+\lambda+1}\right]$ for each $\lambda=0,1,2, \ldots$, then for $t \in\left(t_{j+\lambda}, t_{j+\lambda+1}\right]$, we have

$$
x^{(2 n-1)}(t) \geq \prod_{t_{j} \leq t_{k}<t} a_{k}^{[2 n-1]} x^{(2 n-1)}\left(t_{j}\right)>0 .
$$

The assertion (a) is thus proved.

Next, we will prove the result of (b) to be true. Without loss of generality, we may assume that $x^{(i)}(t)>0$ and $x^{(i+1)}(t) \geq 0$ for $t \geq t_{0}$. We assert there exists some $j$ such that $x^{(i-1)}\left(t_{j}\right)>0$ for $t_{j} \geq t_{0}$. If this is not true, then for any $t_{k}>t_{0}$, we have $x^{(i-1)}\left(t_{k}\right) \leq 0$. Since $x^{(i-1)}(t)$ is increasing on intervals of the form $\left(t_{k}, t_{k+1}\right]$, we see that $x^{(i-1)}(t) \leq 0$ for $t \geq t_{0}$. By $x^{(i)}(t)>0, x^{(i+1)}(t) \geq 0$, and $t \in\left(t_{k}, t_{k+1}\right]$, we have that $x^{(i)}(t)$ is nondecreasing on $\left(t_{k}, t_{k+1}\right]$. For $t \in\left(t_{1}, t_{2}\right]$, we have

$$
x^{(i)}(t) \geq x^{(i)}\left(t_{1}^{+}\right)
$$

In particular,

$$
x^{(i)}\left(t_{2}\right) \geq x^{(i)}\left(t_{1}^{+}\right)
$$

Similarly, for $t \in\left(t_{2}, t_{3}\right]$, we have

$$
x^{(i)}(t) \geq x^{(i)}\left(t_{2}^{+}\right) \geq a_{2}^{(i)} x^{(i)}\left(t_{2}\right) \geq a_{2}^{(i)} x^{(i)}\left(t_{1}^{+}\right) .
$$

By induction, we know that

$$
x^{(i)}(t) \geq \prod_{t_{1}<t_{k}<t} a_{k}^{(i)} x^{(i)}\left(t_{1}^{+}\right), \quad t>t_{1}, \quad t \neq t_{k} .
$$

From condition (ii), we have

$$
x^{(i-1)}\left(t_{k}^{+}\right) \geq b_{k}^{(i-1)} x^{(i-1)}\left(t_{k}\right), \quad k=2,3, \ldots
$$

Set $u(t)=-x^{(i-1)}(t)$. Then from (36) and (37), we see that

$$
\begin{aligned}
& u^{\prime}(t) \leq-\prod_{t_{1}<t_{k}<t} a_{k}^{(i)} x^{(i)}\left(t_{1}^{+}\right), \quad t>t_{1}, t \neq t_{k}, \\
& u\left(t_{k}^{+}\right) \leq b_{k}^{(i-1)} u\left(t_{k}\right), \quad k=2,3, \ldots .
\end{aligned}
$$

It follows from Lemma 12 that

$$
\begin{aligned}
u(t) & \leq u\left(t_{1}^{+}\right) \prod_{t_{1}<t_{k}<t} b_{k}^{(i-1)}-x^{(i)}\left(t_{1}^{+}\right) \int_{t_{1}}^{t} \prod_{s<t_{k}<t} b_{k}^{(i-1)} \prod_{t_{1}<t_{k}<t} a_{k}^{(i)} d s \\
& =\prod_{t_{1}<t_{k}<t} b_{k}^{(i-1)}\left\{u\left(t_{1}^{+}\right)-x^{(i)}\left(t_{1}^{+}\right) \int_{t_{1}}^{t} \prod_{t_{1}<t_{k}<s} \frac{a_{k}^{(i)}}{b_{k}^{(i-1)}} d s\right\} ;
\end{aligned}
$$

that is,

$$
\begin{aligned}
x^{(i-1)}(t) \geq \prod_{t_{1}<t_{k}<t} & b_{k}^{(i-1)}, \\
& \times\left\{x^{(i-1)}\left(t_{1}^{+}\right)+x^{(i)}\left(t_{1}^{+}\right) \int_{t_{1}}^{t} \prod_{t_{1}<t_{k}<s} \frac{a_{k}^{(i)}}{b_{k}^{(i-1)}} d s\right\} .
\end{aligned}
$$

Note that $a_{k}^{(i)}>0, b_{k}^{(i)}>0$, and the first equality of condition (iii) holds. Thus, we get $x^{(i-1)}(t)>0$ for all sufficiently large $t$. The relation $x^{(i-1)}(t) \leq 0$ leads to a contradiction. So there exists some $j$ such that $t_{j}>t_{0}$ and $x^{(i-1)}\left(t_{j}\right)>0$. Then

$$
x^{(i-1)}\left(t_{j}^{+}\right) \geq a_{j}^{(i-1)} x^{(i-1)}\left(t_{j}\right)>0 .
$$

Since $x^{(i)}(t)>0$, then for every positive integer $m$, we have that $x^{(i-1)}(t)$ is increasing on $\left(t_{j+m-1}, t_{j+m}\right]$. For $\left(t_{j}, t_{j+1}\right]$, we have

$$
x^{(i-1)}(t) \geq x^{(i-1)}\left(t_{j}^{+}\right)>0 .
$$

In particular,

$$
x^{(i-1)}\left(t_{j+1}\right) \geq x^{(i-1)}\left(t_{j}^{+}\right)>0 .
$$

Similarly, for $t \in\left(t_{j+1}, t_{j+2}\right]$, we have

$$
x^{(i-1)}(t) \geq x^{(i-1)}\left(t_{j+1}^{+}\right) \geq a_{j+1}^{(i-1)} x^{(i-1)}\left(t_{j+1}\right)>0 .
$$

By induction, for $\left(t_{j+m-1}, t_{j+m}\right]$, we have

$$
x^{(i-1)}(t)>0 \text {. }
$$

Summing up the above discussion, we know that there exists some $T_{1} \geq T$ such that

$$
x^{(i-1)}(t)>0, \quad t \geq T_{1} .
$$

The proof of Lemma 14 is complete.

Remark 15. We may prove in similar manners the following statements.

$\left(\mathrm{a}^{\prime}\right)$ If we replace the condition (a) in Lemma 14 “ $x^{(2 n)}(t)>$ 0 and $\left(r(t) x^{(2 n)}(t)\right)^{\prime} \geq 0$ for $t \geq T$ " with " $x^{(2 n)}(t)<$ 0 and $\left(r(t) x^{(2 n)}(t)\right)^{\prime} \leq 0$ for $t \geq T$," then under conditions (i)-(iii), there exists some $T_{1} \geq T$ such that $x^{(2 n-1)}(t)<0$ for $t \geq T_{1}$. 
$\left(\mathrm{b}^{\prime}\right)$ If we replace the condition (b) in Lemma 14 " $x^{(i)}(t)>$ 0 and $x^{(i+1)}(t) \geq 0$ for $t \geq T$ " with " $x^{(i)}(t)<0$ and $x^{(i+1)}(t) \leq 0$ for $t \geq T$, "then under conditions (i)(iii), there exists some $T_{1} \geq T$ such that $x^{(i-1)}(t)<0$ for $t \geq T_{1}$.

Lemma 16. Suppose conditions (i)-(iii) hold. Let $x=x(t)$ be a solution of (3).

(a) If there exists some $T \geq t_{0}$ such that $x(t)>0$ and $\left(r(t) x^{(2 n)}(t)\right)^{\prime}<0$ for $t \geq T$, then $x^{(2 n)}(t)>0$ for all sufficiently large $t$.

(b) If there exists $i \in\{1,2, \ldots, 2 n\}$ and some $T \geq t_{0}$ such that $x(t)>0$ and $x^{(i)}(t)<0$ for $t \geq T$, then $x^{(i-1)}(t)>$ 0 for all sufficiently larget.

Proof. First of all, we will prove the result of (a) to be true. We assert that $x^{(2 n)}(t)>0$ for any $t_{k} \geq T$. If this is not true, then there exists some $t_{j} \geq T$ such that $x^{(2 n)}\left(t_{j}\right) \leq 0$. Since $r(t)>$ 0 and $r(t) x^{(2 n)}(t)$ are strictly decreasing on $\left(t_{j+m}, t_{j+m+1}\right]$ for $m=0,1,2, \ldots$ and for $t \in\left(t_{j}, t_{j+1}\right]$, we have

$$
r(t) x^{(2 n)}(t)<r\left(t_{j}\right) x^{(2 n)}\left(t_{j}^{+}\right) \leq a_{j}^{(2 n)} r\left(t_{j}\right) x^{(2 n)}\left(t_{j}\right) \leq 0 .
$$

Similarly, for $t \in\left(t_{j+1}, t_{j+2}\right]$, we have

$$
\begin{array}{r}
r(t) x^{(2 n)}(t)<r\left(t_{j+1}\right) x^{(2 n)}\left(t_{j+1}^{+}\right) \\
\leq a_{j}^{(2 n)} a_{j+1}^{(2 n)} r\left(t_{j}\right) x^{(2 n)}\left(t_{j}\right) \leq 0 .
\end{array}
$$

We can easily prove that, for any positive integer $n \geq 2$ and $t \in\left(t_{j+n}, t_{j+n+1}\right]$, we have

$$
r(t) x^{(2 n)}(t)<a_{j}^{(2 n)} a_{j+1}^{(2 n)} \ldots a_{j+n}^{(2 n)} r\left(t_{j}\right) x^{(2 n)}\left(t_{j}\right) \leq 0 .
$$

Hence, $x^{(2 n)}(t)<0$ for $t \geq t_{j+1}$. By the result (a) of Remark 13, for sufficiently large $t$, we have $x^{(2 n-1)}(t)<0$. Using the result (b) of Remark 13 repeatedly, for all sufficiently large $t$, we get $x(t)<0$, which is contrary to $x(t)>0$ for $t \geq T$. Hence we have $x^{(2 n)}\left(t_{k}\right)>0$ for any $t_{k} \geq T$. So we get $x^{(2 n)}(t)>0$ for all sufficiently large $t$.

Next, we will prove the result of (b) to be true. We assert that $x^{(i-1)}\left(t_{k}\right)>0$ for any $t_{k} \geq T$. If this is not true, then there exists some $t_{j} \geq T$ such that $x^{(i-1)}\left(t_{j}\right)<0$. Since $x^{(i-1)}(t)$ is strictly monotony decreasing on $\left(t_{j+n}, t_{j+n+1}\right]$ for $n=0,1,2, \ldots$ and for $t \in\left(t_{j}, t_{j+1}\right]$, we have

$$
x^{(i-1)}(t)<x^{(i-1)}\left(t_{j}^{+}\right) \leq a_{j}^{(i-1)} x^{(i-1)}\left(t_{j}\right) \leq 0 .
$$

Similarly, for $t \in\left(t_{j+1}, t_{j+2}\right]$, we have

$$
x^{(i-1)}(t)<x^{(i-1)}\left(t_{j+1}^{+}\right) \leq a_{j}^{(i-1)} a_{j+1}^{(i-1)} x^{(i-1)}\left(t_{j}\right) \leq 0 .
$$

We can easily prove that for any positive integer $n \geq 2$ and $t \in\left(t_{j+n}, t_{j+n+1}\right]$, we have

$$
x^{(i-1)}(t)<a_{j}^{(i-1)} \ldots a_{j+1}^{(i-1)^{(i-1)}} x^{(i-1)}\left(t_{j}\right) \leq 0 .
$$

Hence, $x^{(i-1)}(t)<0$ for $t \geq t_{j+1}$. By the result $\left(\mathrm{b}^{\prime}\right)$ of Remark 8, for sufficiently large $t$, we have $x^{(i-2)}(t)<0$. Similarly, by using the result $\left(\mathrm{b}^{\prime}\right)$ of Remark 8 again, we can conclude that for all sufficiently large $t, x(t)<0$. That is contrary with $x(t)>0$ for $t \geq T$. Hence, we have $x^{(i-1)}\left(t_{k}\right)>0$ for any $t_{k} \geq T$. So we get $x^{(i-1)}(t)>0$ for all sufficiently large $t$.

The proof of Lemma 16 is complete.

Lemma 17. Suppose conditions (i)-(iii) hold. Let $x=x(t)$ be a solution of (3). Suppose that $T \geq t_{0}$ and $x(t)>0$ for $t \geq T$. Then there exists some $T^{\prime} \geq T$ and $l \in\{0,2,4, \ldots, 2 n\}$ such that for $t \geq T^{\prime}$,

$$
\begin{gathered}
x^{(i)}(t)>0, \quad i=0,1, \ldots, l \\
(-1)^{(i-1)} x^{(i)}(t)>0, \quad i=l+1, \ldots, 2 n ; \\
\left(r(t) x^{(2 n)}(t)\right)^{\prime}<0 .
\end{gathered}
$$

Proof. Let $x(t)>0$ for $t \geq T \geq t_{0}$. By (3) and condition (i), we have

$$
\left(r(t) x^{(2 n)}(t)\right)^{\prime}=-f(t, x) \leq-p(t) \varphi(x)<0 .
$$

By the result (a) of Lemma 16, there exists some $T_{1} \geq T$ such that $x^{(2 n)}(t)>0$ for $t \geq T_{1}$. Without loss of generality, we may let $x^{(2 n)}(t)>0$ for $t \geq t_{0}$. Then $x^{(2 n-1)}(t)$ is strictly increasing on $\left(t_{k}, t_{k+1}\right]$. If for any $t_{k}, x^{(2 n-1)}\left(t_{k}\right)<0$, then $x^{(2 n-1)}(t)<0$ for $t \geq T_{1}$. If there exists some $t_{j}$ such that $x^{(2 n-1)}\left(t_{j}\right) \geq 0$, since $x^{(2 n-1)}(t)$ is strictly monotony increasing and $a_{k}^{[2 n-1]}>$ 0 , then $x^{(2 n-1)}(t)>0$ for $t>t_{j}$. Thus, there exists some $T_{2} \geq$ $T_{1}$ such that $x^{(2 n-1)}(t)>0$ for $t \geq T_{2}$. So one of the following statements holds:

$$
\begin{aligned}
& \left(A_{1}\right) \quad x^{(2 n)}(t)>0, \quad x^{(2 n-1)}(t)>0, \quad t \geq T_{2} \\
& \left(B_{1}\right) \quad x^{(2 n)}(t)>0, \quad x^{(2 n-1)}(t)<0, \quad t \geq T_{2} .
\end{aligned}
$$

If (55) holds, then by the result (b) of Lemma 14, $x^{(2 n-2)}(t)>0$ for all sufficiently large $t$. Using the result (b) of Lemma 14 repeatedly, for all sufficiently large $t$, we can conclude that

$$
x^{(2 n)}(t)>0, \quad x^{(2 n-1)}(t)>0, \ldots, x^{\prime}(t)>0, \quad x(t)>0 .
$$

If (56) holds, by Lemma 16, we have $x^{(2 n-3)}(t)<0$ for all sufficiently large $t$. Similarly, there exists some $T_{3} \geq T_{2}$ such that one of the following statements holds:

$$
\begin{aligned}
& \left(A_{2}\right) \quad x^{(2 n-2)}(t)>0, \quad x^{(2 n-3)}(t)>0, \quad t \geq T_{3} ; \\
& \left(B_{2}\right) \quad x^{(2 n-2)}(t)>0, \quad x^{(2 n-3)}(t)<0, \quad t \geq T_{3} .
\end{aligned}
$$


Repeating the discussion above, we can eventually get that there exist some $T^{\prime} \geq T$ and $l \in\{0,2,4, \ldots, 2 n\}$ such that for $t \geq T^{\prime}$,

$$
\begin{gathered}
x^{(i)}(t)>0, \quad i=0,1, \ldots, l \\
(-1)^{(i-1)} x^{(i)}(t)>0, \quad i=l+1, \ldots, 2 n ; \\
\left(r(t) x^{(2 n)}(t)\right)^{\prime}<0 .
\end{gathered}
$$

The proof of Lemma 17 is complete.

Lemma 18 (see [13]). Suppose for $t>0, x=x(t)$ is continuous at $t \neq t_{k}$, left-continuous at $t=t_{k}$, and $\lim _{t \rightarrow t_{k}^{+}} x(t)$ exists for $k=1,2, \ldots$. Further, assume that

$\left(\mathrm{H}_{2}\right)$ there exists $\bar{t} \in R^{+}$, such that $x(t)>0(<0)$ for $t \geq \bar{t}$;

$\left(\mathrm{H}_{3}\right) x(t)$ is nonincreasing (resp., nondecreasing) on $\left(t_{k}, t_{k+1}\right]$ for $k=1,2, \ldots$;

$\left(\mathrm{H}_{4}\right) \sum_{k=1}^{+\infty}\left[x\left(t_{k}^{+}\right)-x\left(t_{k}\right)\right]$ is convergent.

Then $\lim _{t \rightarrow \infty} x(t)=r$ exists and $r \geq 0$ (resp. $\left.\leq 0\right)$.

We now turn to the proof of Theorem 1. Without loss of generality, we may assume that $k_{0}=1$. If (3) has a nonoscillatory solution $x=x(t)$, we may assume that $x(t)>0$ for $t \geq t_{0}$. By Lemma 17, there exists a $T \geq t_{0}$ and $l \in\{0,2,4, \ldots, 2 n\}$ such that for $t \geq T$, (53) holds. Next, we rewrite (53) as

$$
\begin{aligned}
& x^{\prime}(t)<0, \ldots, x^{(2 n)}(t)>0, \\
& \left(r(t) x^{(2 n)}(t)\right)^{\prime}<0 \text { for } l=0 ; \\
& x^{\prime}(t)>0, \ldots, x^{(l)}(t)>0, \quad(-1)^{(i)} x^{(i)}(t)>0, \\
& \left(r(t) x^{(2 n)}(t)\right)^{\prime}<0 \text { for } l \geq 2 .
\end{aligned}
$$

If (60) holds, then we see that the conditions $\left(\mathrm{H}_{2}\right)$ and $\left(\mathrm{H}_{3}\right)$ of Lemma 18 are satisfied. Furthermore, note that $\sum_{k=1}^{+\infty}\left(b_{k}^{[0]}-\right.$ 1) $<+\infty$ and $b_{k}^{[0]} \geq a_{k}^{[0]} \geq 1$, then one has

$$
\prod_{k=1}^{+\infty} b_{k}^{[0]}<+\infty .
$$

Since $x^{\prime}(t)<0$ and $t \geq T$, one obtains for any $t_{k}>T$,

$$
x\left(t_{k}\right) \leq \prod_{T<t_{j}<t_{k}} b_{j}^{[0]} x\left(T^{+}\right) .
$$

By (62) and (63), we know $\left\{x\left(t_{k}\right)\right\}$ is bounded. Thus, there exists $M>0$ such that $\left|x\left(t_{k}\right)\right| \leq M$. It follows from condition (ii) that

$$
\left|x\left(t_{k}^{+}\right)-x\left(t_{k}\right)\right| \leq\left|b_{k}^{[0]}-1\right|\left|x\left(t_{k}\right)\right| \leq M\left(b_{k}^{[0]}-1\right) \text {. }
$$

From (64) and note that $\sum_{k=1}^{+\infty}\left(b_{k}^{[0]}-1\right)$ is convergent, we know that $\sum_{k=1}^{+\infty}\left[x\left(t_{k}^{+}\right)-x\left(t_{k}\right)\right]$ is convergent. Therefore, the condition $\left(H_{4}\right)$ of Lemma 18 is also satisfied. By Lemma 18, we have $\lim _{t \rightarrow+\infty} x(t)=r \geq 0$. We assert that $r=0$. If $r>0$, then there exists $T_{1} \geq T$, such that for any $t \geq T_{1}, x(t)>r / 2>0$.
Note that $\varphi^{\prime}(x) \geq 0$; hence we may see that $\varphi(x(t)) \geq \varphi(r / 2)$ for $t \geq T_{1}$. Let $\Phi(t)=r(t) x^{(2 n)}(t)$. Then $\Phi(t)>0$ for $t \geq T_{1}$. By conditions (i), (ii), and (3), one has for $t \geq T_{1}$,

$$
\begin{aligned}
\Phi^{\prime}(t) & =-f(t, x) \leq-p(t) \varphi(x(t)) \\
& \leq-\varphi\left(\frac{r}{2}\right) p(t), \quad t \neq t_{k}, \\
\Phi\left(t_{k}^{+}\right) & =r\left(t_{k}^{+}\right) x^{(2 n)}\left(t_{k}^{+}\right) \leq b_{k}^{[2 n]} r\left(t_{k}\right) x^{(2 n)}\left(t_{k}\right) \\
& \leq b_{k}^{[2 n]} \Phi\left(t_{k}\right), \quad t_{k} \geq T_{1} .
\end{aligned}
$$

From (65) and Lemma 12, one gets for $t \geq T_{1}$,

$\Phi(t)$

$$
\begin{aligned}
& \leq \Phi\left(T_{1}^{+}\right) \prod_{T_{1}<t_{k}<t} b_{k}^{[2 n]}-\varphi\left(\frac{r}{2}\right) \int_{T_{1}}^{t} \prod_{s<t_{k}<t} b_{k}^{[2 n]} p(s) d s \\
& =\prod_{T_{1}<t_{k}<t} b_{k}^{[2 n]}\left(\Phi\left(T_{1}^{+}\right)-\varphi\left(\frac{r}{2}\right) \int_{T_{1}}^{t} \prod_{T_{1}<t_{k}<s} \frac{1}{b_{k}^{[2 n]}} p(s) d s\right) .
\end{aligned}
$$

It is easy to see from (7) and (66) that $\Phi(t)<0$ for sufficiently large $t$. This is contrary to $\Phi(t)>0$ for $t \geq T_{1}$. Thus, $r=0$; that is, $\lim _{t \rightarrow+\infty} x(t)=0$.

If (61) holds, then let $\Psi(t)=r(t) x^{(2 n)}(t) / \varphi(x(t))$. Then $\Psi(t)>0$ for $t \geq T$. By (3) and condition (i), one has for $t \geq T$,

$$
\begin{aligned}
\Psi^{\prime}(t) & =\frac{-f(t, x(t))}{\varphi(x(t))}-\frac{r(t) x^{(2 n)}(t) \varphi^{\prime}(x(t)) x^{\prime}(t)}{\varphi^{2}(x(t))} \\
& \leq \frac{-f(t, x(t))}{\varphi(x(t))} \leq-p(t), \quad t \neq t_{k} .
\end{aligned}
$$

From the conditions (i) and (ii) and note that $a_{k}^{[0]} \geq 1$, we know that

$$
\begin{aligned}
\Psi\left(t_{k}^{+}\right) & =\frac{r\left(t_{k}^{+}\right) x^{(2 n)}\left(t_{k}^{+}\right)}{\varphi\left(x\left(t_{k}^{+}\right)\right)} \leq \frac{r\left(t_{k}\right) b_{k}^{[2 n]} x^{(2 n)}\left(t_{k}\right)}{\varphi\left(a_{k}^{[0]} x\left(t_{k}\right)\right)} \\
& \leq b_{k}^{[2 n]} \frac{r\left(t_{k}\right) x^{(2 n)}\left(t_{k}\right)}{\varphi\left(x\left(t_{k}\right)\right)}=b_{k}^{[2 n]} \Psi\left(t_{k}\right) .
\end{aligned}
$$

From (67), (68), and Lemma 12, one gets for $t \geq T$,

$$
\begin{aligned}
\Psi(t) & \leq \Psi\left(T^{+}\right) \prod_{T<t_{k}<t} b_{k}^{[2 n]}-\int_{T}^{t} \prod_{u<t_{k}<t} b_{k}^{[2 n]} p(u) d u \\
& =\prod_{T<t_{k}<t} b_{k}^{[2 n]}\left\{\Psi\left(T^{+}\right)-\int_{T}^{t} \prod_{T<t_{k}<u} \frac{1}{b_{k}^{[2 n]}} p(u) d u\right\} .
\end{aligned}
$$

It is easy to see from (7) and (69) that $\Psi(t)<0$ for sufficiently large $t$. This is contrary to $\Psi(t)>0$ for $t \geq T$. Thus, every solution of (3) is oscillatory. The proof of Theorem 1 is complete. 
We now give the proof of Theorem 2. Without loss of generality, we may assume that $k_{0}=1$. If (3) has a nonoscillatory solution $x=x(t)$, we may assume that $x(t)>0$ for $t \geq t_{0}$. By Lemma 17, there exists a $T \geq t_{0}$ and $l \in\{0,2,4, \ldots, 2 n\}$ such that for $t \geq T$, (53) holds. Next, we may rewrite (53) as (60) and (61).

If (60) holds, then note that $b_{k}^{[0]} \leq 1$. Since $x(t)$ is decreasing on $\left(t_{j+l}, t_{j+l+1}\right]$ for $t_{j} \geq T$ and each $l=0,1,2, \ldots$, one has for $t \in\left(t_{j+l}, t_{j+l+1}\right)$,

$$
\begin{aligned}
x(t) & <x\left(t_{j+l}^{+}\right) \leq \cdots \leq x\left(t_{j+1}\right) \\
& <x\left(t_{j}^{+}\right) \leq b_{j}^{[0]} x\left(t_{j}\right) \leq x\left(t_{j}\right) .
\end{aligned}
$$

So, since $x(t)$ is decreasing and bounded on $\left(t_{j},+\infty\right)$, we know that $x(t)$ is convergent as $t \rightarrow+\infty$. Let $\lim _{t \rightarrow+\infty} x(t)=r$. Then $r \geq 0$. We assert that $r=0$. If $r>0$, then there exists $T_{1} \geq T$ such that for $t \geq T_{1}, x(t)>r / 2>0$. Since $\varphi^{\prime}(x) \geq 0$, one has $\varphi(x(t)) \geq \varphi(r / 2)$. By (3) and condition (i), one has for $t \geq T$,

$$
\begin{aligned}
\left(r(t) x^{(2 n)}(t)\right)^{\prime} & =-f(t, x) \leq-p(t) \varphi(x(t)) \\
& \leq-\varphi\left(\frac{r}{2}\right) p(t)<0, \quad t \neq t_{k} .
\end{aligned}
$$

From condition (ii) and noting that $b_{k}^{[2 n]} \leq 1$, one has

$$
\begin{aligned}
r\left(t_{k}^{+}\right) x^{(2 n)}\left(t_{k}^{+}\right) & \leq b_{k}^{[2 n]} r\left(t_{k}\right) x^{(2 n)}\left(t_{k}\right) \\
& \leq r\left(t_{k}\right) x^{(2 n)}\left(t_{k}\right), \quad t_{k} \geq T_{1} .
\end{aligned}
$$

By (71), (72), and Lemma 12, one has for $t \geq T_{1}$,

$$
r(t) x^{(2 n)}(t) \leq r\left(T_{1}\right) x^{(2 n)}\left(T_{1}^{+}\right)-\varphi\left(\frac{r}{2}\right) \int_{T_{1}}^{t} p(s) d s .
$$

It is easy to see from (8) and (73) that $x^{(2 n)}(t)<0$ for sufficiently large $t$. This is contrary to $x^{(2 n)}(t)>0$ for $t \geq T$. Thus $r=0$, that is, $\lim _{t \rightarrow+\infty} x(t)=0$;

If (61) holds, then let $\Psi(t)=r(t) x^{(2 n)}(t) / \varphi(x(t))$. We see that $\Psi(t)>0$ for $t \geq T$. By (3) and the condition (i), one gets for $t \geq T$

$$
\begin{aligned}
\Psi^{\prime}(t) & =-\frac{f(t, x(t))}{\varphi(x(t))}-\frac{r(t) x^{(2 n)}(t) \varphi^{\prime}(x(t)) x^{\prime}(t)}{\varphi^{2}(x(t))} \\
& \leq-\frac{f(t, x(t))}{\varphi(x(t))} \leq-p(t), \quad t \neq t_{k} .
\end{aligned}
$$

From the conditions (i) and (ii), we know that

$$
\begin{aligned}
\Psi\left(t_{k}^{+}\right) & =\frac{r\left(t_{k}\right) x^{(2 n)}\left(t_{k}^{+}\right)}{\varphi\left(x\left(t_{k}^{+}\right)\right)} \leq \frac{r\left(t_{k}\right) b_{k}^{[2 n]} x^{(2 n)}\left(t_{k}\right)}{\varphi\left(a_{k}^{[0]} x\left(t_{k}\right)\right)} \\
& \leq \frac{b_{k}^{[2 n]}}{\varphi\left(a_{k}^{[0]}\right)} \frac{r\left(t_{k}\right) x^{(2 n)}\left(t_{k}\right)}{\varphi\left(x\left(t_{k}\right)\right)} \leq \Psi\left(t_{k}\right) .
\end{aligned}
$$

From (74), (75), and Lemma 12, one gets for $t \geq T$,

$$
\Psi(t) \leq \Psi\left(T^{+}\right)-\int_{T}^{t} p(s) d s
$$

It is easy to see from (8) and (76) that $\Psi(t)<0$ for sufficiently large $t$. This is contrary to $\Psi(t)>0$ for $t \geq T$. Thus, every solution of (3) is oscillatory. The proof of Theorem 2 is complete.

Finally, we give the proof of Theorem 3. Without loss of generality, we may assume that $k_{0}=1$. If (3) has a nonoscillatory solution $x=x(t)$, we may assume that $x(t)>0$ for $t \geq t_{0}$. By Lemma 17, there exists a $T \geq t_{0}$ and $l \in$ $\{0,2,4, \ldots, 2 n\}$ such that for $t \geq T,(53)$ hold. Next, we rewrite (53) as (60) and (61).

If $(60)$ holds, then we see that the conditions $\left(\mathrm{H}_{2}\right)$ and $\left(\mathrm{H}_{3}\right)$ of Lemma 18 are satisfied. Furthermore, since $x^{\prime}(t)<0$ for $t \geq$ $T$, we see that there exists some $t_{i} \geq T$ such that for any $t_{k}>t_{i}$,

$$
x\left(t_{k}\right) \leq \prod_{t_{i}<t_{j}<t_{k}} b_{j}^{[0]} x\left(t_{i}^{+}\right) .
$$

Since $\left\{\prod_{k=1}^{n} b_{k}^{[0]}\right\}$ is bounded, in view of (77), we know that $\left\{x\left(t_{k}\right)\right\}$ is bounded. Thus, there exists $M_{1}>0$, such that $\left|x\left(t_{k}\right)\right| \leq M_{1}$. It follows from the condition (ii) that

$$
\begin{aligned}
\left|x\left(t_{k}^{+}\right)-x\left(t_{k}\right)\right| & \leq \max \left\{\left|a_{k}^{[0]}-1\right|,\left|b_{k}^{[0]}-1\right|\right\}\left|x\left(t_{k}\right)\right| \\
& \leq M_{1} \max \left\{\left|a_{k}^{[0]}-1\right|,\left|b_{k}^{[0]}-1\right|\right\} .
\end{aligned}
$$

By (78), we know that $\sum_{k=1}^{+\infty}\left[x\left(t_{k}^{+}\right)-x\left(t_{k}\right)\right]$ is convergent. Therefore, the condition $\left(H_{4}\right)$ of Lemma 18 is also satisfied. By Lemma 18, we know that $\lim _{t \rightarrow+\infty} x(t)=r \geq 0$. We assert that $r=0$. If $r>0$, then there exists $T_{1} \geq T$, such that for $t \geq T_{1}, x(t)>r / 2>0$. Since $\varphi^{\prime}(x) \geq 0$, we see that $\varphi(x(t)) \geq$ $\varphi(r / 2)$ for $t \geq T_{1}$. By $b_{k}^{[2 n]} \leq a_{k}^{[0]}$, the boundedness of $\left\{\prod_{k=1}^{n} b_{k}^{[0]}\right\}$ and the condition (ii), we know that $\left\{\prod_{k=1}^{n} b_{k}^{[2 n]}\right\}$ is bounded. Note that $\left(r(t) x^{(2 n)}(t)\right)^{\prime}<0$ for $t \geq T_{1}$. So we may also see that there exists $M_{2}>0$ such that $\left|r\left(t_{k}\right) x^{(2 n)}\left(t_{k}\right)\right| \leq M_{2}$. Therefore, one has

$$
\left|\left(b_{k}^{[2 n]}-1\right) r\left(t_{k}\right) x^{(2 n)}\left(t_{k}\right)\right| \leq M_{2}\left|b_{k}^{[2 n]}-1\right| .
$$

By (3) and the condition (i), one has

$$
\left(r(t) x^{(2 n)}(t)\right)^{\prime}=-f(t, x) \leq-p(t) \varphi(x(t))<0, \quad t \neq t_{k} .
$$


Integrating (80) from $T_{1}$ to $t$, it follows from (79) and the condition (ii) that

$$
\begin{aligned}
r(t) & x^{(2 n)}(t)-r\left(T_{1}\right) x^{(2 n)}\left(T_{1}^{+}\right) \\
\leq & \sum_{T_{1}<t_{k}<t} r\left(t_{k}\right)\left[x^{(2 n)}\left(t_{k}^{+}\right)-x^{(2 n)}\left(t_{k}\right)\right] \\
& -\varphi\left(\frac{r}{2}\right) \int_{T_{1}}^{t} p(s) d s \\
\leq & \sum_{T_{1}<t_{k}<t}\left|\left(b_{k}^{[2 n]}-1\right) r\left(t_{k}\right) x^{(2 n)}\left(t_{k}\right)\right| \\
& -\varphi\left(\frac{r}{2}\right) \int_{T_{1}}^{t} p(s) d s \\
\leq & \sum_{T_{1}<t_{k}<t} M_{2}\left|b_{k}^{[2 n]}-1\right|-\varphi\left(\frac{r}{2}\right) \int_{T_{1}}^{t} p(s) d s .
\end{aligned}
$$

Since $\sum_{k=1}^{+\infty}\left|b_{k}^{[2 n]}-1\right|$ is convergent, it is easy to see from (9) and $(81)$ that $x^{(2 n)}(t)<0$ for sufficiently larget. This is contrary to $x^{(2 n)}(t)>0$ for $t \geq T$. Thus $r=0$; that is, $\lim _{t \rightarrow+\infty} x(t)=0$.

If (61) holds, then let $\Psi(t)=r(t) x^{(2 n)}(t) / \varphi(x(t))$. We see that $\Psi(t)>0$ for $t \geq T$. Similar to the proof of (76), we also obtain

$$
\Psi(t) \leq \Psi\left(T^{+}\right)-\int_{T}^{t} p(s) d s .
$$

It is easy to see from (9) and (82) that $\Psi(t)<0$ for sufficiently large $t$. This is contrary to $\Psi(t)>0$ for $t \geq T$. Thus, every solution of (3) is oscillatory. The proof of Theorem 3 is complete.

\section{References}

[1] V. Lakshmikantham, D. D. Bainov, and P. S. Simeonov, Theory of Impulsive Differential Equations, World Scientific, Singapore, 1989.

[2] J. Shen and J. Yu, "On nonlinear delay differential equations with impulsive perturbations," Mathematical Applications, vol. 9, pp. 272-277, 1996.

[3] D. Bainov, Y. I. Domshlak, and P. S. Simeonov, "On the oscillation properties of first-order impulsive differential equations with a deviating argument," Israel Journal of Mathematics, vol. 98, no. 1, pp. 167-187, 1997.

[4] Y. Chen and W. Feng, "Oscillations of second order nonlinear ODE with impulses," Journal of Mathematical Analysis and Applications, vol. 210, no. 1, pp. 150-169, 1997.

[5] G. Wang, "Oscillations of second order differential equations with impulses," Annals of Differential Equations, vol. 14, pp. 295306, 1998

[6] H. Li and C. Yeh, "Oscillation and nonoscillation criteria for second order linear differential equations," Mathematische Nachrichten, vol. 194, pp. 171-184, 1998.

[7] M. Peng and W. Ge, "Oscillation criteria for second-order nonlinear differential equations with impulses," Computers and Mathematics with Applications, vol. 39, no. 5-6, pp. 217-225, 2000 .
[8] J. Luo and L. Debnath, "Oscillation of second order nonlinear ODE with impulses," Journal of Mathematical Analysis and Applications, vol. 240, no. 1, pp. 105-114, 1999.

[9] Z. He and W. Ge, "Oscillations of second-order nonlinear impulsive ordinary differential equations," Journal of Computational and Applied Mathematics, vol. 158, no. 2, pp. 397-406, 2003.

[10] Z. Luo and J. Shen, "Oscillation of second order linear differential equations with impulses," Applied Mathematics Letters, vol. 20, no. 1, pp. 75-81, 2007.

[11] C. Hou and S. S. Cheng, "Asymptotic dichotomy in a class of fourth-order nonlinear delay differential equations with damping," Abstract and Applied Analysis, vol. 2009, Article ID 484158, 7 pages, 2009.

[12] K. Wen, G. Wang, and S. Cheng, "Asymptotic dichotomy in a class of third-order nonlinear differential equations with impulses," Abstract and Applied Analysis, vol. 2010, Article ID 562634, 20 pages, 2010.

[13] F. Chen and X. Wen, "Oscillations of n-order Linear differential equation with impulses," Acta Applicandae Mathematicae, vol. 29, pp. 527-541, 2006. 


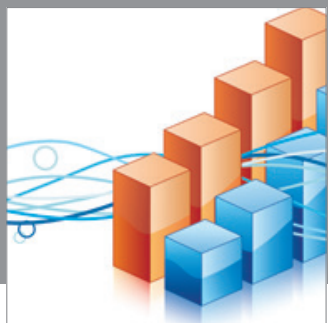

Advances in

Operations Research

mansans

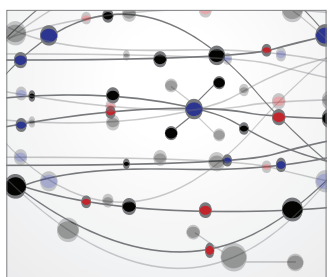

The Scientific World Journal
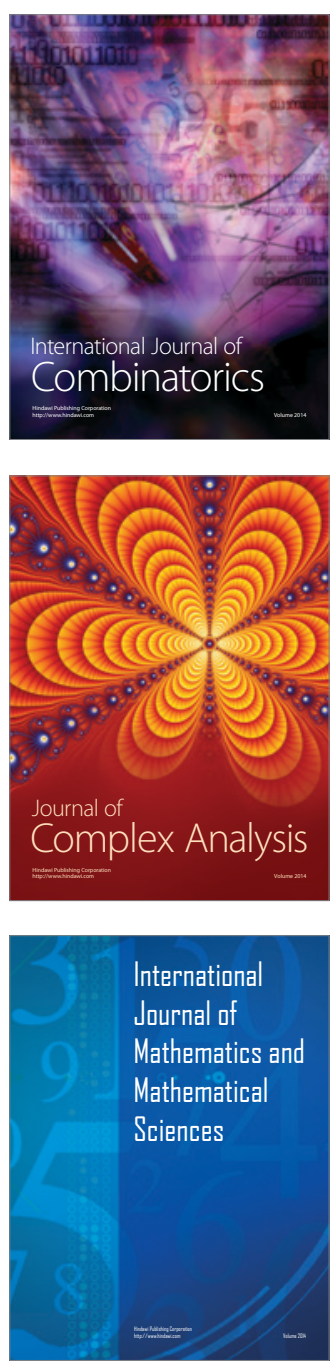
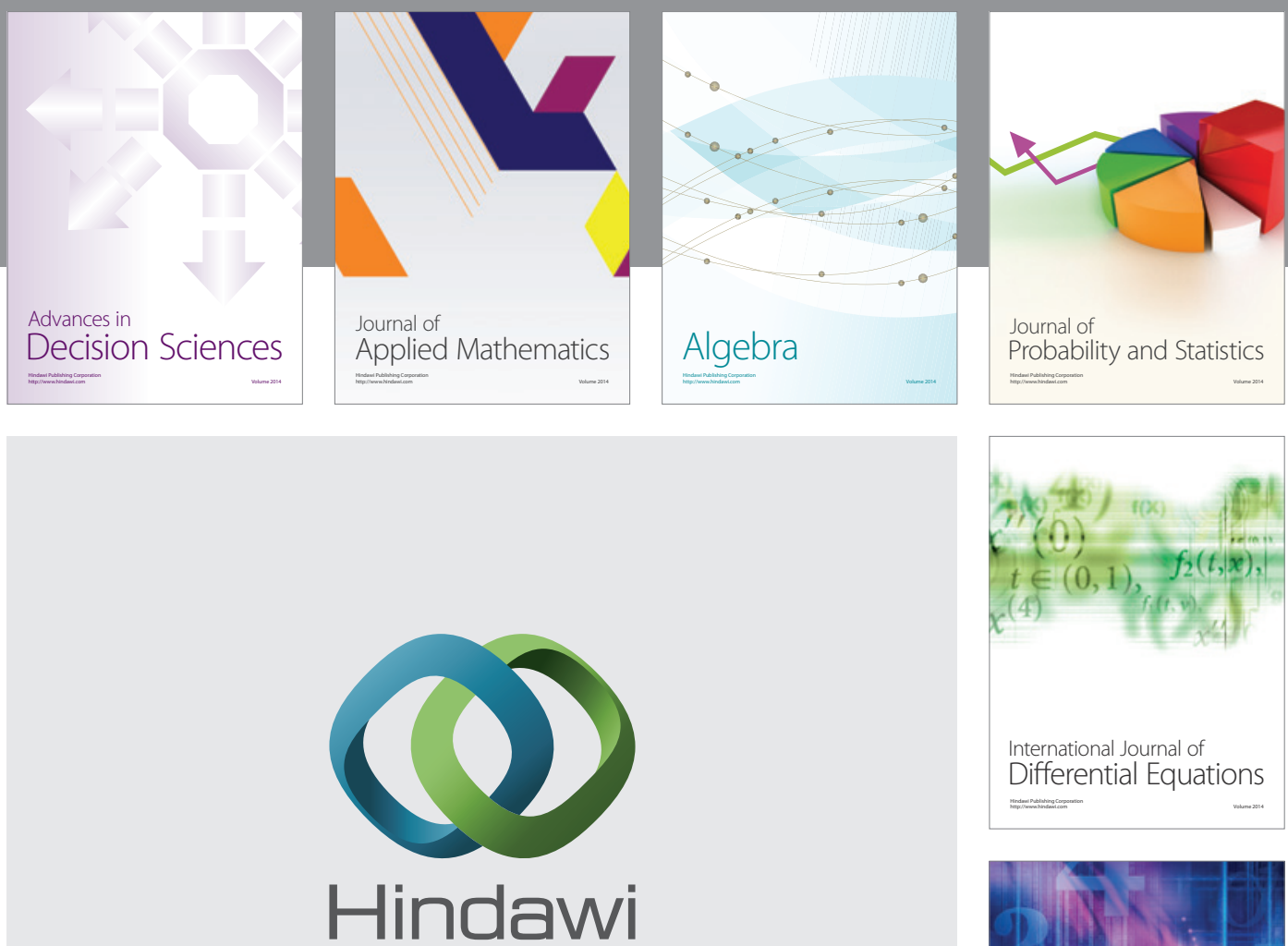

Submit your manuscripts at http://www.hindawi.com
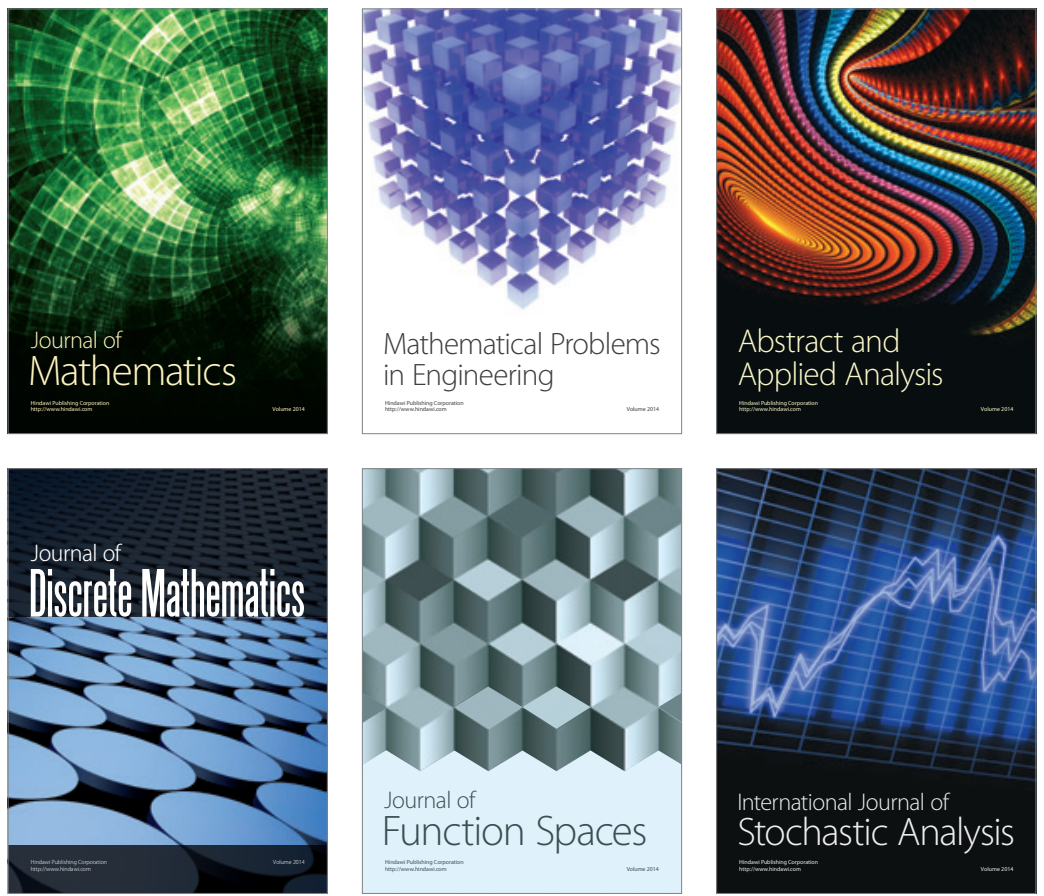

Journal of

Function Spaces

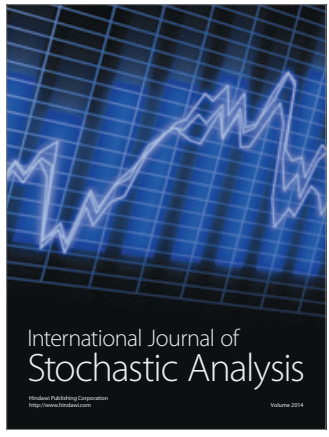

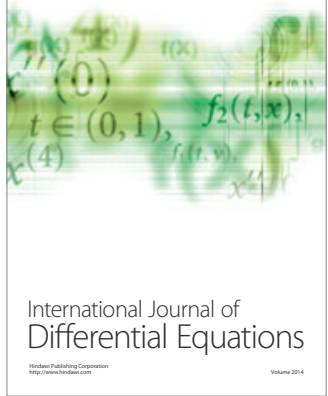
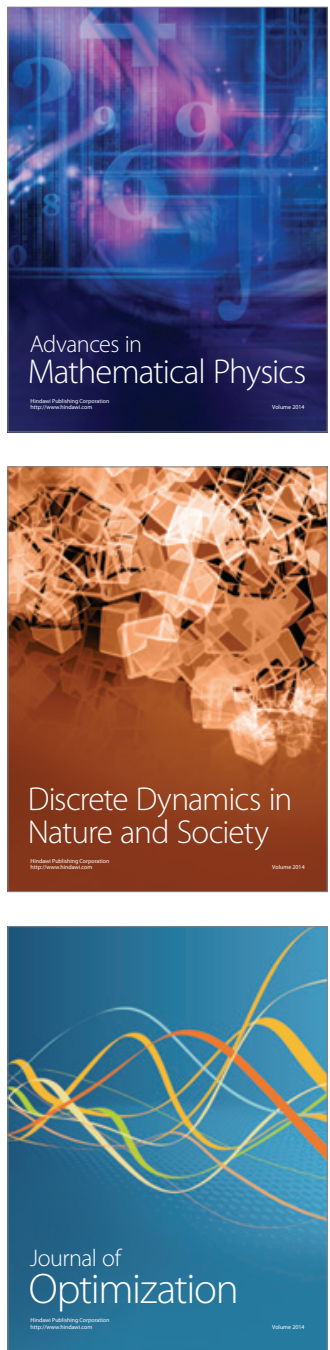